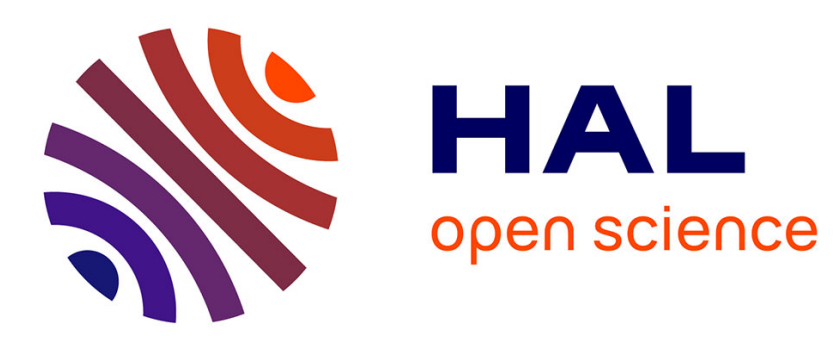

\title{
Synthesis and Photophysical Properties of Porphyrins with Fluorenyl Pendant Arms
}

Samuel Drouet, Christine O Paul-Roth, Gérard Simonneaux

\section{To cite this version:}

Samuel Drouet, Christine O Paul-Roth, Gérard Simonneaux. Synthesis and Photophysical Properties of Porphyrins with Fluorenyl Pendant Arms. Tetrahedron, 2009. hal-02945971

HAL Id: hal-02945971

https://hal-univ-rennes1.archives-ouvertes.fr/hal-02945971

Submitted on 22 Sep 2020

HAL is a multi-disciplinary open access archive for the deposit and dissemination of scientific research documents, whether they are published or not. The documents may come from teaching and research institutions in France or abroad, or from public or private research centers.
L'archive ouverte pluridisciplinaire HAL, est destinée au dépôt et à la diffusion de documents scientifiques de niveau recherche, publiés ou non, émanant des établissements d'enseignement et de recherche français ou étrangers, des laboratoires publics ou privés. 


\title{
Synthesis and Photophysical Properties of Porphyrins with Fluorenyl Pendant Arms
}

\author{
Samuel Drouet ${ }^{\mathrm{a}}$, Christine O. Paul-Roth ${ }^{\mathrm{a}, \mathrm{b} *}$ and Gérard Simonneaux ${ }^{\mathrm{a}}$ \\ ${ }^{a}$ Groupe Ingénierie Chimique \& Molécules pour le Vivant, ICMV- UMR CNRS 6226, \\ Université de Rennes I, 35042 Rennes cedex, France \\ ${ }^{b}$ Institut National des Sciences Appliquées-INSA de Rennes
}

*Corresponding author. Fax: 022323 56 37; Tel.: 0223236372

e-mail: christine.paul@univ-rennes1.fr

\section{Graphical Abstract}

Synthesis and Photophysical Properties of Porphyrins with Fluorenyl Pendant Arms

Samuel Drouet ${ }^{\mathrm{a}}$, Christine O. Paul-Roth ${ }^{\mathrm{a}, \mathrm{b}}$ and Gérard Simonneaux ${ }^{\mathrm{a}}$

${ }^{a}$ Groupe Ingénierie Chimique \& Molécules pour le Vivant, UMR CNRS 6226,

Université de Rennes I, 35042 Rennes cedex, France

${ }^{b}$ Institut National des Sciences Appliquées-INSA de Rennes

*Corresponding author. Fax: 02232356 37; Tel.: 0223236372

e-mail: christine.paul@univ-rennes 1.fr

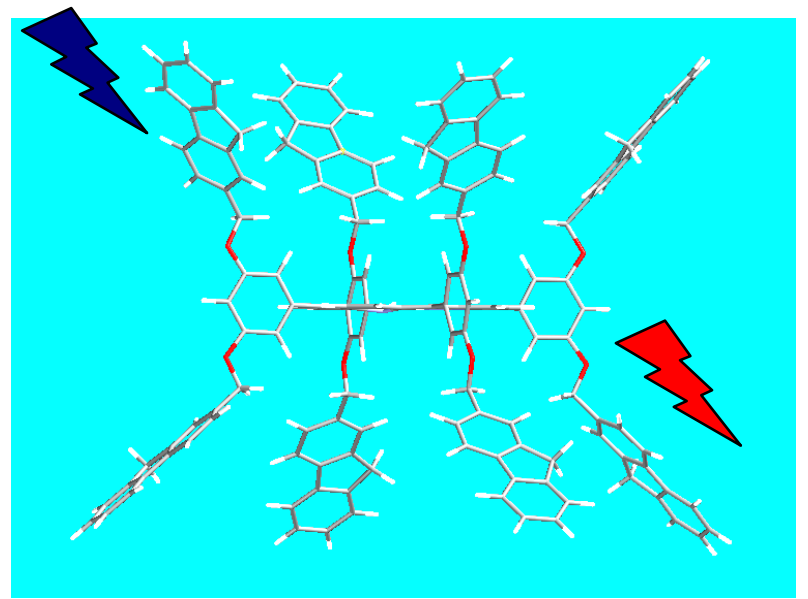




\begin{abstract}
Symmetrical-A ${ }_{4}$-porphyrins bearing four fluorene donor moieties TOFP (5,10,15,20-tetra(4-(2 methyloxyfluorenyl)phenyl)porphyrin as well as eight fluorene arms OOFP $(5,10,15,20-\operatorname{octa}(3,5-(2$ methyloxyfluorenyl)phenyl)porphyrin, were synthesized and characterized. Preliminary photophysical properties are reported. In comparison to the reference tetraphenylporphyrin TPP, the luminescence properties are slightly improved. The fluorescence quantum yields of tetrafluorenylporphyrin TOFP (1) and octafluorenylporphyrin
\end{abstract}

OOFP (2) are 0.10 and 0.13 , respectively.

Keywords: Fluorescence; Porphyrins; fluorene, light harvesting, quantum yield

\title{
1. Introduction
}

Porphyrin systems, as energy acceptors, have been covalently linked to donor units like carotenoids ${ }^{1,2}$ or anthracenes ${ }^{3}$ to modelize photosynthetic systems and to develop efficient molecular devices. The porphyrin skeleton permits to attach easily four energy donor arms in the near periphery, and such a light-harvesting system can be expected to show an antenna effect. Antenna systems comprising a central porphyrin linked to four peripheral photonharvesting hydrocarbon moieties have been reported. For example, naphthalene, ${ }^{4}$ anthracene ${ }^{5}$ or phenanthrene ${ }^{6}$ groups have been linked directly to four meso-carbons of the porphyrin and more recently a series of star-shaped porphyrins bearing pendant linear oligofluorene arms, have also been reported. ${ }^{7,8}$ In the previous donor-acceptor (D-A) system described, the energy donors are linked directly to the porphyrin periphery. For antenna effect, it is better to have a multicomponent structure in which the donors and acceptors retain their individual characteristics. For a realistic description of the photosynthetic antenna function, a porphyrinbased model system should exhibit high local concentrations of the light-harvesting chromophores. All of these considerations indicate that a molecular pentad system, in which a porphyrin acceptor is linked, via spacers, to four donor hydrocarbons, forms a suitable choice

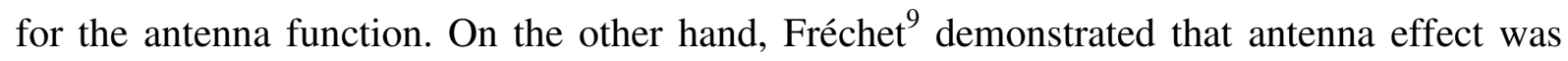
facilitated in dendritic case versus the corresponding linear case. Thus, more recently, lightharvesting donor two-photon absorbing chromophores (TPAC) with metalated porphyrin cores were synthesised in this group. ${ }^{10}$ The same year, the synthesis of hyperbranched polymers containing porphyrin core possessing fluorene arms has been reported, for tuning 
the optical properties of hyperbranched polymers through the modification of the end groups. $^{11}$

\section{(Insert Fig. 1 here please)}

In our previous papers, we have reported the synthesis of a free macrocycle possessing four pendant fluorene arms directly connected at the meso-positions (TFP) and evidenced that the ruthenium(II) complexes of this type are very efficient heterogeneous catalysts. ${ }^{12-15}$ Recently, we focused on the photophysical properties of such porphyrins possessing four identical fluorene pendant arms. ${ }^{16,17}$ These porphyrins exhibited high quantum yields (22\%), so a complete family of relevant porphyrins was studied to investigate this high luminescence efficiency. It was demonstrated therein the good capacity of the fluorenyl units to enhance quantum yields by increasing the radiative process. ${ }^{18}$

The present report deals with the design of a new building block based on fluorenyl porphyrins with the aim to exploit this capacity to enhance quantum yields and to combine this advantage with Fréchet's style dendritic architecture in order to improve energy transfer. The target is to obtain highly luminescent organic compounds, by the design of porphyrins possessing fluorenyl arms using dendritic synthesis. In more details, in this paper, we present the synthesis of systems in which a 5,10,15,20-tetraphenylporphyrin (TPP) is linked, via ether bridges, to four and eight fluorene donor moieties, compounds 1 and $\mathbf{2}$ respectively (Fig. 1), and in a second part preliminary photophysical results are also reported.

\section{Results and discussion}

\subsection{Synthesis}

2-hydroxyl-methyl-fluorene (7) was obtained by reduction of fluorene-2carboxaldehyde with sodium borohydride in ethanol. After 1 hour reaction time followed by extraction with dichloromethane, the crude product was purified by column chromatography to yield 7 as a white solid (96\%). This alcohol was then brominated with carbon tetrabromide in presence of triphenylphosphine in dichloromethane. The mixture was stirred overnight, concentrated, and purified by column chromatography to give 2-bromomethyl-fluorene (8) as a white solid (55\%) (Scheme 1). 
The two intermediate porphyrins, (TOHPP) and (OOHPP), were obtained from the methylated porphyrins analogs, porphyrin 5 (TOMePP) and 6 (OOMePP) respectively by reaction with $\mathrm{BBr}_{3}{ }^{19}$

Meso-(5,10,15,20-tetra(4-(2 methyloxyfluorenyl)phenyl)porphyrin 1 was obtained by condensation from the prepared bromide 8 (5 eq) and TOHPP (1 eq) in dry THF using potassium carbonate as base in presence of 18-crown-6 (Scheme 2). This solution was stirred under argon at reflux for one day. The reaction time was monitored by UV spectroscopy. After purification by cristallization, the desired porphyrin $\mathbf{1}$ was obtained as a brown-violet solid (95\%). Meso-(5,10,15,20-tetra(4-(3,5 dimethyloxyfluorenyl)phenyl)porphyrin 2 was obtained by condensation from the prepared bromide 8 (10 eq) and OOHPP (1 eq) in dry THF using potassium carbonate as base in presence of 18-crown-6 (Scheme 2). This solution was stirred under argon at reflux for nine days. Completion of the reaction time was monitored by UV spectroscopy. After purification by column chromatography on silica gel, the desired porphyrin 2 was obtained as a brown-violet solid (38\%).

\section{(Insert Scheme 2 here please)}

These new porphyrins $\mathbf{1}$ and $\mathbf{2}$ were characterized by NMR, UV-visible and mass spectrometry. The hydrogen and carbon atom-labeling scheme for the porphyrin ligands $\mathbf{1}$ and 2 is shown in Figure 2.

In the conditions used, the non-substituted fluorene arm is stable but, often alkyl chains have been introduced on the position- 9 of the fluorene units to increase the solubility. ${ }^{8}$

\section{(Insert Fig. 2 here please)}

\subsection{Optimised geometries}

The calculated optimised geometries ("SPARTAN Pro, Molecular Mechanics and Quantum Chemical Calculations", PM3 $)^{20}$ for porphyrin derivatives $\mathbf{1}$ and $\mathbf{2}$ are shown in Figures 3a and 3b, respectively. These molecular modelling data clearly show for the new compound 1, that the trans fluorenyl arms are on the same side of the porphyrin core, in a alternate way whereas the macrocyclic core is essentially planar. Actually, it is known that the 
meso-aryl groups are not orthogonal to the porphyrin plane, but slightly tilted, ${ }^{21}$ allowing the meso group to develop some conjugative interaction with the main porphyrin framework. Thus, in spite of the large dihedral angle between the plane of the phenyl ring and the porphyrin $\pi$ system in the TPP series, conjugation exists to some extent and is affected by the substituents on the phenyl ring. This conjugative interaction of the aromatic meso-substituents can explain the color shift observed for various derivatives. Surprisingly, the calculated optimised geometries showed that the phenyl groups are almost perpendicular to the porphyrin core for $\mathbf{1}$. Indeed, the dihedral angles between the phenyl groups and the porphyrin core are $89^{\circ}$, whereas for TFP this angle is $64^{\circ}$, and for TPP $60^{\circ}$. Similarly the fluorenyl arms are also perpendicular to the porphyrin core. This special arrangement gives to the monomer a wheel aspect. So the interactions between the porphyrin and fluorenyl will be enhanced because the distance is relatively short, around 7-10 Á. $^{20}$. Similarly for 2 , the phenyl group appears also perpendicular to the porphyrin core, and the molecular modelling data clearly show for the new compound 2, that the four fluorenyl arms, on the same side of the porphyrin core, are disposed like a calix, so the entire molecule appears as a double calix. In this case the distance between the porphyrin and fluorenyl arms is short as well. These calculated conformations are only representative of the prevailing ones, given that these structures are certainly fluxional in solution. In consequence, other local energy minima might also exist in solution.

(Insert Fig. 3 here please)

\subsection{Photophysical properties}

2.3.1 Electronic spectra-The UV-visible spectra of $\mathbf{1}$ and $\mathbf{2}$ exhibit an intense Soret band with a maximum absorption similar around $423 \mathrm{~nm}$ (Fig. 4). This band is slightly red shifted compared to $417 \mathrm{~nm}$ for TPP (4), but not as much as for TFP (3) (426 nm). This tendency in red shifting is observed as well for the Q bands. The $\pi-\pi^{*}$ absorption in the UV range is clearly apparent, due to the presence of fluorene. For compound $\mathbf{1}$, the four fluorene arms absorb in the UV range with a maximum absorption peak at $272 \mathrm{~nm}$, for compound 2 possessing eight arms the absorption is stronger with a maximum at $263 \mathrm{~nm}$. Finally we have the following shift for the absorption of the Soret band, for these compounds:

$$
\lambda_{3}>\lambda_{1}=\lambda_{2}>\lambda_{4}
$$


2.3.2 Emission- The emission spectrum of compound 1, after excitation in the Soret band reveals a strong red fluorescence with a peak maximum at $663 \mathrm{~nm}$ and a weak shoulder at 728 nm (Fig. 5). Concerning, the emission spectrum of compound 2, after excitation in the Soret band, a strong red emission at $656 \mathrm{~nm}$ and a shoulder at $721 \mathrm{~nm}$ is observed (Fig. 5). After excitation in bounded-fluorene absorption (272 nm for compound $\mathbf{1}$ and $263 \mathrm{~nm}$ for compound 2), the emission spectra reveal red fluorescence and almost no residual emission of the fluorene for both compounds. Thus, there is apparently a good energy transfer between fluorene and porphyrin, since essentially red emission of porphyrin is observed in comparison to blue emission of fluorene around $300 \mathrm{~nm}$. In fact, almost all the UV energy absorbed by the fluorine units is emitted by the porphyrin core.

The excitation spectra obtained after exciting in the strongest emission band around $660 \mathrm{~nm}$, reveals an emission from the Soret state, the three first Q states, as well as from the fluorene. This indicates that excitation over all the $200-650 \mathrm{~nm}$ region leads to the population of all the fluorescent excited states of the porphyrin. Notably the fluorene chromophore involved in the UV absorption process becomes also strongly apparent under such excitation conditions. For comparison, the excitation spectra of compound $\mathbf{1}$ and $\mathbf{2}$ are shown in fig. $\mathbf{5}$.

Thus for the new compounds $\mathbf{1}$ and $\mathbf{2}$, the luminescence can be modulated in a large range of excitation wavelengths from UV to red, to finally obtain the desired red emission.

\section{(Insert Fig. 5 here please)}

2.3.3 Fluorescence quantum yields-The fluorescence quantum yields of these compounds were next determined by comparing with a calibration standard of compound 4 (TPP) in degassed toluene solution presenting a fluorescence quantum yield of $0.12,{ }^{22}$ preferentially to a benzene solution with a fluorescence quantum yield of $0.13^{23}$ (in this latter case, different refractive indices of the solvents used in the standard and sample must be corrected). ${ }^{24}$ In consequence the correction made for the difference in refractive indices of solvents is in this case not necessary. The quantum yield was calculated from the following equation:

$$
\Phi_{\mathrm{s}}=\Phi_{\mathrm{TPP}} \times\left(\mathrm{F}_{\mathrm{s}} / \mathrm{F}_{\mathbf{T P P}}\right) \times\left(\mathrm{A}_{\mathbf{T P P}} / \mathrm{A}_{\mathrm{s}}\right) \times\left(\mathrm{n}_{\mathbf{T P P}} / \mathrm{n}_{\mathrm{s}}\right)^{2}
$$


In the above expression, $\Phi_{\mathrm{s}}$ is the fluorescent quantum yield of the new compound, $F$ is the integration of the emission intensities, $n$ is the index of refraction of the solution, and $A$ is the absorbance of the solution at the exciting wavelength. The subscripts TPP and s denote the reference (TPP) and unknown samples, respectively. ${ }^{25}$

Values of quantum yield of free ligands 1, 2, 3 and $\mathbf{4}$ are reported in Table 1. All measurements were obtained under an argon atmosphere to limit photo-oxidative degradation (Table 1). Compound 2 presents a luminescence quantum yield (13\%), which is similar to that of the reference 4 (12\%). Apparently the high quantum yield (24\%) observed for the compound possessing fluorene arms directly connected on the meso positions TFP are not maintained when a phenyl intermediate substituted in position 3 and 5 is introduced. So a system in which a 5,10,15,20-tetraphenylporphyrin (TPP) is linked, via ether bridges, to eight fluorene donor moieties in position 3 and 5, presents the same luminescence efficiency as the parent TPP compound. Similarly, compound 1 presents a quantum yield of $10 \%$. Further photophysical investigations will be undertaken to rationalize these results. ${ }^{26}$

\section{(Insert Table 1 here please)}

\section{Conclusion}

In summary, we have synthesized and characterized two new porphyrins TOFP, 1 and OOFP, 2 bearing four and eight fluorenyl pendant arms at the meso-positions, respectively. These two porphyrins emit essentially red light after selective UV or visible irradiation. In case of UV irradiation, these systems comprising a central porphyrin like TPP linked to peripheral photon-harvesting fluorene moieties have been shown to act as efficient antennas. Porphyrin TOFP, 1 shows similar emission, in terms of solution-state fluorescence quantum yield, compared to the reference TPP, 4, whereas compound OOFP, 2 is slightly enhanced. These results suggest that a judicious choice of meso-aryl dendrons can allow the properties of porphyrins to be optimized for OLEDs, both in terms of efficiency and color tuning. Based on our recent results of anodic electropolymerization of monomers $3,{ }^{12} 4^{27}$ and $6{ }^{28}$ we now expect to obtain a polymeric 3D network after connections of the four or even eight fluorenyl pendant arms. This should allow growing a polymeric 3D structure from such macrocycle, possessing several connecting points for each monomer. Compounds $\mathbf{1}$ and $\mathbf{2}$ constitute therefore an interesting building block to access new emissive organic materials. 


\section{Experimental}

\subsection{General}

All reactions were performed under argon and were magnetically stirred. Solvents were distilled from appropriate drying agent prior to use, $\mathrm{CH}_{2} \mathrm{Cl}_{2}$ from $\mathrm{CaH}_{2}, \mathrm{CHCl}_{3}$ from $\mathrm{P}_{2} \mathrm{O}_{5}$ and all other solvents were HPLC grade. Commercially available reagents were used without further purification unless otherwise stated. ${ }^{1} \mathrm{H}$ NMR and ${ }^{13} \mathrm{C} \mathrm{NMR}$ in $\mathrm{CDCl}_{3}$ were recorded using Bruker 200 DPX, 300 DPX and 500 DPX spectrometers. The chemical shifts are referenced to internal TMS. The assignments were performed by 2D NMR experiments: COSY (Correlation Spectroscopy), HMBC (Heteronuclear Multiple Bond Correlation) and HMQC (Heteronuclear Multiple Quantum Coherence). UV spectra were recorded on UVIKON XL from Biotek instruments. PL emission was recorded on a Photon Technology International (PTI) apparatus coupled on an 814 Photomultiplier Detection System, Lamp Power Supply 220B and MD-5020. Pyrrole and 2-fluorenecarboxaldehyde were purchased from Aldrich and were used as received. Reference $\mathbf{T F P}=$ tetrafluorenylporphyrin, $\mathbf{T P P}=$ tetraphenylporphyrin. Purity of compounds $\mathbf{1}$ and $\mathbf{2}$ has been checked by GPC. Size exclusion chromatography (SEC) of compounds was performed in THF at $20{ }^{\circ} \mathrm{C}$ using a Polymer Laboratories PL-GPC 50 plus apparatus (PLgel $5 \mu \mathrm{m}$ MIXED-C $300 \times 7.5 \mathrm{~mm}, 1.0 \mathrm{ml} \mathrm{min}{ }^{-1}$, RI and Dual angle LS detector (PL-LS 45/90).

\subsection{Synthesis of the arms}

\subsubsection{Synthesis of 2-hydroxyl-methyl-fluorene (7)}

To a solution of the commercial fluorene-2-carboxaldehyde $(500 \mathrm{mg}, 2.57 \mathrm{mmol})$ in ethanol $(40 \mathrm{ml})$ was added sodium borohydride $(117 \mathrm{mg}, 3.09 \mathrm{mmol})$ at $0^{\circ} \mathrm{C}$ during a period of $10 \mathrm{~min}$. The reaction mixture was stirred at room temperature for $1 \mathrm{~h}$ and then poured into water, followed by extraction with dichloromethane. The organic layer was washed with brine, dried over anhydrous $\mathrm{MgSO}_{4}$ and the solvent was removed. The residue was purified by column chromatography on silica gel $\left(1: 1 \mathrm{CH}_{2} \mathrm{Cl}_{2} /\right.$ pentane $)$ to yield $476 \mathrm{mg}$ of a white solid (96 \%). ${ }^{1} \mathbf{H}-\mathbf{N M R}\left(200 \mathrm{MHz}, \mathrm{CDCl}_{3}\right): 7.81\left(\mathrm{~d},{ }^{3} J_{\mathrm{HH}}=8.0 \mathrm{~Hz}, 2 \mathrm{H}\right), 7.58\left(\mathrm{~d},{ }^{3} J_{\mathrm{HH}}=8.0 \mathrm{~Hz}, 2 \mathrm{H}\right)$, $7.40\left(\mathrm{~d},{ }^{3} J_{\mathrm{HH}}=10.0 \mathrm{~Hz}, 2 \mathrm{H}\right), 7.33(\mathrm{~s}, 1 \mathrm{H}), 4.80$ (s, 2H, $\left.\mathrm{CH}_{2}-\mathrm{OH}\right), 3.94$ (s, 2H, $\mathrm{CH}_{2 \text { fluorene }) .}$ 
To a solution of alcohol $7(0.5 \mathrm{~g}, 2.56 \mathrm{mmol})$ in dichloromethane $(10 \mathrm{ml})$ was added carbon tetrabromide (936 $\mathrm{mg}, 2.82 \mathrm{mmol}$ ) followed by the portion-wise addition of triphenylphosphine $(739 \mathrm{mg}, 2.82 \mathrm{mmol})$. The mixture was stirred at $0^{\circ} \mathrm{C}$ for $1 \mathrm{~h}$ and then at room temperature for overnight, concentrated, and purified by column chromatography on silica gel (9:1 pentane/ $\mathrm{CH}_{2} \mathrm{Cl}_{2}$ ) to give $366 \mathrm{mg}$ (55\%) of $\mathbf{8}$ as a white solid: ${ }^{1} \mathbf{H}-\mathbf{N M R}$ (200 $\left.\mathrm{MHz}, \mathrm{CDCl}_{3}\right): 7.81\left(\mathrm{~d},{ }^{3} J_{\mathrm{HH}}=8.0 \mathrm{~Hz}, 1 \mathrm{H}\right), 7.75\left(\mathrm{~d},{ }^{3} J_{\mathrm{HH}}=7.7 \mathrm{~Hz}, 1 \mathrm{H}\right), 7.59\left(\mathrm{~d},{ }^{3} J_{\mathrm{HH}}=8.8 \mathrm{~Hz}\right.$, $2 \mathrm{H}), 7.43\left(\mathrm{~d},{ }^{3} \mathrm{~J}_{\mathrm{HH}}=7.9 \mathrm{~Hz}, 1 \mathrm{H}\right), 7.38\left(\mathrm{~d},{ }^{3} J_{\mathrm{HH}}=8.0 \mathrm{~Hz}, 1 \mathrm{H}\right), 7.37(\mathrm{~s}, 1 \mathrm{H}), 4.91\left(\mathrm{~s}, 2 \mathrm{H}, \mathrm{CH}_{2}-\mathrm{Br}\right)$,

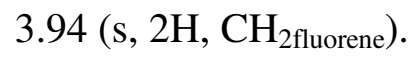

\subsection{Synthesis of the porphyrins}

\subsubsection{Synthesis of porphyrin 1}

TOFP meso-(5,10,15,20-tetra(4-(2methyloxyfluorenyl)phenyl)porphyrin $1 \quad$ : 2 bromomethyl-fluorene (191 mg, $736 \mu \mathrm{mol}$ ), tetrakis (4-hydroxyphenyl)-porphyrin TOHPP (100 mg, $147 \mu \mathrm{mol}), \mathrm{K}_{2} \mathrm{CO}_{3}(162 \mathrm{mg}, 1.18 \mathrm{mmol})$ and 18-crown-6 (40 mg, $67 \mu \mathrm{mol}$ ), were dissolved in $10 \mathrm{~mL}$ of dry THF and stirred under argon at reflux for $16 \mathrm{~h}$. The reaction was cooled to room temperature and the mixture was filtrated. The insoluble violet powder was washed with THF $(100 \mathrm{~mL})$, water $(100 \mathrm{~mL})$ and pentane $(100 \mathrm{~mL})$. The precipitate was dried over $\mathrm{MgSO}_{4}$ and in oven $\left(50^{\circ} \mathrm{C}\right)$ under vacuum to yield a violet solid $(95 \%)$. The purity of compound 1 has been checked by TLC plate and by GPC (SEC).

${ }^{1} \mathbf{H}$-NMR (solubilized by acidic deuterated TFA in $\left.\mathrm{CDCl}_{3}\right): 8.54\left(\mathrm{~d},{ }^{3} J_{\mathrm{HH}}=8.4 \mathrm{~Hz}, 8 \mathrm{H}, \mathrm{H}_{\mathrm{B}}\right.$ ), $8.52\left(\mathrm{~s}, 8 \mathrm{H}\right.$, pyrrole), $7.96\left(\mathrm{~d},{ }^{3} J_{\mathrm{HH}}=7.8 \mathrm{~Hz}, 4 \mathrm{H}, \mathrm{H}_{4^{\prime}}\right), 7.90\left(\mathrm{~d},{ }^{3} J_{\mathrm{HH}}=7.4 \mathrm{~Hz}, 4 \mathrm{H}, \mathrm{H}_{5^{\prime}}\right), 7.87(\mathrm{~s}$, $\left.4 \mathrm{H}, \mathrm{H}_{1^{\prime}}\right), 7.68\left(\mathrm{~d},{ }^{3} J_{\mathrm{HH}}=7.8 \mathrm{~Hz}, 4 \mathrm{H}, \mathrm{H}_{3^{\prime}}\right), 7.65\left(\mathrm{~d},{ }^{3} J_{\mathrm{HH}}=8.4 \mathrm{~Hz}, 8 \mathrm{H}, \mathrm{H}_{\mathrm{D}}\right), 7.64\left(\mathrm{~d},{ }^{3} J_{\mathrm{HH}}=7.3 \mathrm{~Hz}\right.$, $\left.4 \mathrm{H}, \mathrm{H}_{8^{\prime}}\right), 7.46\left(\mathrm{t},{ }^{3} J_{\mathrm{HH}}=7.6 \mathrm{~Hz}, 4 \mathrm{H}, \mathrm{H}_{6^{\prime}}\right), 7.38\left(\mathrm{t},{ }^{3} J_{\mathrm{HH}}=7.4 \mathrm{~Hz}, 4 \mathrm{H}, \mathrm{H}_{7^{\prime}}\right), 5.52\left(\mathrm{~s}, 8 \mathrm{H}, \mathrm{H}_{\mathrm{H}-\mathrm{H}^{\prime}}\right)$, 4.06 (s, 8H, $\left.\mathrm{H}_{9},-9,\right)$.

${ }^{13} \mathbf{C}$-NMR (solubilized by acidic deuterated TFA in $\left.\mathrm{CDCl}_{3}\right): 160.82\left(\mathrm{C}_{\mathrm{E}}\right), 146.04\left(\mathrm{C}_{1-4-6-9-11-}\right.$ 14-16-19), 144.18 ( $\left.\mathrm{C}_{9}{ }^{\prime}\right), 143.31\left(\mathrm{C}_{8}{ }^{\prime}\right), 142.18\left(\mathrm{C}_{4}{ }^{\prime}\right), 141.13\left(\mathrm{C}_{5^{\prime \prime}}\right), 140.01\left(\mathrm{C}_{\mathrm{B}}\right), 133.53\left(\mathrm{C}_{\mathrm{A}}\right)$, $134.86\left(\mathrm{C}_{2}{ }^{\prime}\right), 127.84\left(\mathrm{C}_{2-3-7-8-12-13-17-18}\right), 127.03\left(\mathrm{C}_{7}\right), 126.91\left(\mathrm{C}_{6^{\prime}}\right), 126.69\left(\mathrm{C}_{3^{\prime}}\right), 125.18\left(\mathrm{C}_{8^{\prime}}\right)$, $124.69\left(\mathrm{C}_{1}\right), 122.10\left(\mathrm{C}_{5-10-15-20}\right), 120.11\left(\mathrm{C}_{5}\right), 120.20\left(\mathrm{C}_{4}\right), 114.95\left(\mathrm{C}_{\mathrm{D}}\right), 70.97\left(\mathrm{C}_{\mathrm{H}}\right), 37.02$ $\left(\mathrm{C}_{9},\right)$

Analysis: calcd for $\mathrm{C}_{100} \mathrm{H}_{70} \mathrm{~N}_{4} \mathrm{O}_{4} \cdot 1.5 \mathrm{CHCl}_{3}$ : C, 77.02; H, 5.32; N, 3.54; S, 0, found: C, 77.44; $\mathrm{H}, 4.76$; N, 3.37; S, 0. MALDI TOF-MS : calcd for $\mathrm{C}_{100} \mathrm{H}_{70} \mathrm{~N}_{4} \mathrm{O}_{4}: 1390.5500[\mathrm{MH}]^{+}$, found $1390.3650[\mathrm{MH}] . \mathbf{U V}-\mathbf{v i s}\left(\mathbf{C H}_{\mathbf{2}} \mathbf{C l}_{2}\right): \lambda_{\max / \mathrm{nm}} 263$ (fluorene, $\varepsilon_{263}=74$ 800), 291 (fluorene, $\varepsilon_{291}$ $=45000$ ), 304 (fluorene, $\left.\varepsilon_{304}=53200\right), 423$ (Soret band, $\left.\varepsilon_{423}=213600\right), 516\left(\mathrm{Q}_{1}\right.$ band, $\varepsilon_{516}=$ 
14 800), $551\left(\mathrm{Q}_{2}\right.$ band, $\left.\varepsilon_{551}=11400\right), 590\left(\mathrm{Q}_{3}\right.$ band, $\left.\varepsilon_{590}=8200\right)$ and $647 \mathrm{~nm}\left(\mathrm{Q}_{4}\right.$ band, $\varepsilon_{647}=$ 11 400). UV-vis (0.02 mL TFA/1L $\left.\mathbf{C H}_{2} \mathbf{C l}_{2}\right): \lambda_{\max / \mathrm{nm}} 263$ (fluorene, $\varepsilon_{263}=105$ 600), 291 (fluorene, $\varepsilon_{291}=53$ 200),, 304 (fluorene, $\varepsilon_{304}=63$ 000), 451 (Soret band, $\varepsilon_{51}=373$ 000), 682 $\left(\mathrm{Q}_{1}\right.$ band, $\left.\varepsilon_{682}=58600\right), 700\left(\mathrm{Q}_{3}\right.$ band, $\left.\varepsilon_{700}=41000\right)$.

\subsubsection{Synthesis of porphyrin 2}

OOFP: meso-(5,10,15,20-tetra(4-(3,5dimethyloxyfluorenyl)phenyl)porphyrin 2 : 2 bromomethyl-fluorene (157 mg, $606 \mu \mathrm{mol}$ ), tetrakis (3',5'-dihydroxyphenyl)-porphyrin OOHPP (50 mg, $67 \mu \mathrm{mol}), \mathrm{K}_{2} \mathrm{CO}_{3}(149 \mathrm{mg}, 1.07 \mathrm{mmol})$ and 18-crown-6 (18 mg, $\left.67 \mu \mathrm{mol}\right)$, were dissolved in $5 \mathrm{ml}$ of dry THF and stirred under argon at reflux for 9 days. The reaction was cooled to room temperature, and the mixture was poured in a separatory funnel containing $50 \mathrm{ml}$ of $\mathrm{CH}_{2} \mathrm{Cl}_{2}$ and washed with water $(100 \mathrm{~mL})$ twice and brine $(100 \mathrm{~mL})$. The organic phase was dried over $\mathrm{MgSO}_{4}$ and the solvent was removed. The residue was purified by column chromatography on silica gel $\left(9: 1 \mathrm{CH}_{2} \mathrm{Cl}_{2} /\right.$ pentane) to yield $56 \mathrm{mg}$ of a brown solid (38 \%). The purity of compound $\mathbf{2}$ has been checked by TLC plate after column chromatography and by GPC (SEC).

${ }^{1} \mathbf{H}-\mathbf{N M R}\left(\mathrm{CDCl}_{3}\right): 8.83\left(\mathrm{~s}, 8 \mathrm{H}\right.$, pyrrole), $7.81\left(\mathrm{~d},{ }^{3} J_{\mathrm{HH}}=7.9 \mathrm{~Hz}, 8 \mathrm{H}, \mathrm{H}_{4^{\prime}}\right), 7.80\left(\mathrm{~d},{ }^{3} J_{\mathrm{HH}}=7.6 \mathrm{~Hz}\right.$, $\left.8 \mathrm{H}, \mathrm{H}_{5^{\prime}}\right), 7.72\left(\mathrm{~s}, 8 \mathrm{H}, \mathrm{H}_{1^{\prime}}\right), 7.55\left(\mathrm{~d},{ }^{3} J_{\mathrm{HH}}=7.4 \mathrm{~Hz}, 8 \mathrm{H}, \mathrm{H}_{8^{\prime}}\right), 7.54\left(\mathrm{~s}, 8 \mathrm{H}, \mathrm{H}_{\mathrm{B}}\right), 7.52(\mathrm{~d}$, $\left.{ }^{3} J_{\mathrm{HH}}=8.0 \mathrm{~Hz}, 8 \mathrm{H}, \mathrm{H}_{3^{\prime}}\right), 7.40\left(\mathrm{t},{ }^{3} J_{\mathrm{HH}}=7.2 \mathrm{~Hz}, 8 \mathrm{H}, \mathrm{H}_{6}\right), 7.32\left(\mathrm{t},{ }^{3} J_{\mathrm{HH}}=7.2 \mathrm{~Hz}, 8 \mathrm{H}, \mathrm{H}_{7}\right), 7.18$ (t, $\left.{ }^{3} J_{\mathrm{HH}}=2.2 \mathrm{~Hz}, 4 \mathrm{H}, \mathrm{H}_{\mathrm{E}}\right), 5.33$ (s, 16H, $\left.\mathrm{H}_{\mathrm{H}-\mathrm{H}^{\prime}}\right), 3.91$ (s, 16H, $\left.\mathrm{H}_{9}{ }^{\prime} 9^{\prime}\right)$.

${ }^{13}$ C-NMR $\left(\mathrm{CDCl}_{3}\right)$ : $157.997\left(\mathrm{C}_{\mathrm{D}}\right), 147.08\left(\mathrm{C}_{1-4-6-9-11-14-16-19}\right), 143.939\left(\mathrm{C}_{\mathrm{A}}\right), 143.73\left(\mathrm{C}_{9}{ }^{\prime \prime}\right)$, $142.42\left(\mathrm{C}_{8}{ }^{\prime}\right), 141.78\left(\mathrm{C}_{4}{ }^{\prime}\right), 141.32\left(\mathrm{C}_{5}{ }^{\prime}\right), 135.28\left(\mathrm{C}_{2}{ }^{\prime}\right), 130.95\left(\mathrm{C}_{2-3-7-8-12-13-17-18}\right), 126.91\left(\mathrm{C}_{6}\right)$, $126.86\left(\mathrm{C}_{7^{\prime}}\right), 126.69\left(\mathrm{C}_{3}\right), 125.18\left(\mathrm{C}_{8^{\prime}}\right), 124.685\left(\mathrm{C}_{1},\right), 120.033\left(\mathrm{C}_{4},\right), 119.975\left(\mathrm{C}_{5},\right), 119.79$ $\left(\mathrm{C}_{5-10-15-20}\right), 115.275\left(\mathrm{C}_{\mathrm{B}}\right), 102.87\left(\mathrm{C}_{\mathrm{E}}\right), 70.752\left(\mathrm{C}_{\mathrm{H}}\right), 36.904\left(\mathrm{C}_{9}\right)$.

Analysis: calcd for $\mathrm{C}_{156} \mathrm{H}_{108} \mathrm{~N}_{4} \mathrm{O}_{8} \cdot 2 \mathrm{CH}_{3} \mathrm{CO}_{2} \mathrm{Et}: \mathrm{C}, 84.08 ; \mathrm{H}, 5.33 ; \mathrm{N}, 2.39, \mathrm{~S}, 0$ found $\mathrm{C}$, 84.62; H, 6.03; N, 1.57, S, 0. MALDI TOF-MS calcd for $\mathrm{C}_{156} \mathrm{H}_{108} \mathrm{~N}_{4} \mathrm{O}_{8}: 2166.550[\mathrm{MH}]^{+}$, found $2166.596[\mathrm{MH}]^{+}$. UV-vis $\left(\mathbf{C H}_{\mathbf{2}} \mathbf{C l}_{2}\right): \lambda_{\max / \mathrm{nm}} 270$ (fluorene, $\varepsilon_{270}=141700$ ), 292 (fluorene, $\varepsilon_{2912}=64$ 600), 304 (fluorene, $\varepsilon_{304}=71000$ ), 423 (Soret band, $\varepsilon_{423}=245300$ ), 516 $\left(\mathrm{Q}_{1}\right.$ band, $\left.\varepsilon_{516}=10700\right), 551\left(\mathrm{Q}_{2}\right.$ band, $\left.\varepsilon_{551}=2200\right), 592\left(\mathrm{Q}_{3}\right.$ band, $\left.\varepsilon_{592}=2200\right)$ and $653 \mathrm{~nm}$ $\left(\mathrm{Q}_{4}\right.$ band, $\left.\varepsilon_{653}=4600\right)$.

\section{Acknowledgements}


The authors are grateful to K. Kostuas (CTI-UMR 6226), S. Sinbandhit (CRMPO) and P. Le Maux (ICMV-UMR 6226) for their technical assistance and helpful discussions.

\section{References}

1. Gust, D.; Moore, T. A.; Moore, A. L. Acc. Chem. Res. 1993, 26, 198.

2. Osuka, A.; Yamada, H.; Maruyama, K.; Mataga, N.; Asahi, T.; Ohkouchi, M.; Okada, T.; Yamazaki, I.; Nishimura, Y. J. Am. Chem. Soc. 1993, 115, 9439.

3. Effenberger, F.; Schlosser, H.; Baverle, P.; Maier, S.; Port, H.; Wolf, H. C. Angew. Chem. Int. Ed. Engl. 1988, 27, 281.

4. Abraham, R. J.; Hawkes, G. E.; Hudson, M. F.; Smith, K. M. J. Chem. Soc., Perkin. Trans. II 1975, 204.

5. Fonda, H. N.; Gilbert, J. V.; Cormier, R. A.; Sprague, J. R.; Kamioka, K.; Connolly, J. S. J. Phys. Chem. 1993, 97, 7024.

6. Toeibs, A.; Haeberle, N. Justus Liebigs Ann. Chem. 1968, 718, 183.

7. Li, B.; Xu, X.; Sun, M.; Fu, Y.; Yu, G.; Liu, Y.; Bo, Z. Macromolecules 2006, 39, 456-461.

8. Li, B.; Li, J.; Fu, Y.; Bo, Z. J. Am. Chem. Soc. 2004, 126, 3430-3431.

9. Harth, E. M.; Hecht, S.; Helms, B.; Malmstrom, E. E.; Fréchet, J. M.; Hawker, C. J. J. Am. Chem. Soc. 2002, 124, 3926-3938.

10. Oar, M. A.; Serin, J. M.; Fréchet, J. M. Chem. Mater. 2006, 18, 3682-3692.

11. Sun, M.; Bo, Z. Journal of Polymer Science: Part A: Polymer Chemistry 2006, 45, 111-124.

12. Paul-Roth, C.; Rault-Berthelot, J.; Simonneaux, G. Tetrahedron 2004, 60, 1216912175.

13. Simonneaux, G.; Galardon, E.; Paul-Roth, C.; Gulea, M.; Masson, S. J. Organomet. Chem. 2001, 617-618, 360-363.

14. Poriel, C.; Ferrand, Y.; Le Maux, P.; Paul, C.; Rault-Berthelot, J.; Simonneaux, G. Chem. Commun. 2003, 18, 2308-2309.

15. Poriel, C.; Ferrand, Y.; Le Maux, P.; Paul-Roth, C.; Simonneaux, G.; Rault-Berthelot, J. J. Electroanal. Chem. 2005, 583, 92-103.

16. Paul-Roth, C. O.; Simonneaux, G. Tetrahedron Lett. 2006, 47, 3275-3278.

17. Paul-Roth, C. O.; Simonneaux , G. C. R. de Chim. 2006, 9, 1277-1286. 
18. Paul-Roth, C.; Williams, G.; Letessier, J.; Simonneaux , G. Tetrahedron Lett. 2007, $48,4317-4322$.

19. Jiang, D.-L.; Aida, T. J. Am. Chem. Soc. 1998, 120, 10895-10901.

20. Spartan Pro Wavefunction, Inc. Irvine, CA, USA

http://www.wavefun.com, 1999.

21. Shelnutt, J. A.; Kadish, K. M.; Smith, K. M.; Guilard, R. E. The porphyrins, Academic press, New-york, 2000, 7, 167.

22. Owens, J. W.; Smith, R.; Robinson, R.; Robins, M. Inorg. Chim. Acta 1998, 279, 226231.

23. Zang, X. H.; Xie, Z. Y.; Wu, F. P.; Zhou, L. L.; Wong, O. Y.; Lee, C. S.; Kwong, H. L.; Lee, S. T.; Wu, S. K. Chem. Phys. Lett. 2003, 382, 561-566.

24. Quimby, D. J.; Longo, F. R. J. Am. Chem. Soc. 1975, 97, 5111-5117.

25. Demas, J. N.; Crosby, G. A. J. Phys. Chem. 1971, 75, 991-1024.

26. Drouet, S.; Williams, J. A. G.; Paul-Roth, C. 2009, manuscript in preparation.

27. Paul-Roth, C.; Rault-Berthelot, J.; Simonneaux, G.; Poriel, C.; Abdalilah, M.; Letessier, J. J. Electroanal. Chem. 2006, 597, 19-27.

28. Rault-Berthelot, J.; Paul-Roth, C.; Poriel, C.; Juillard, S.; Ballut, S.; Drouet, S.; Simonneaux, G. J. Electroanal. Chem. 2008, 623, 204-214. 


\section{Schemes and Figures Captions}

Scheme 1: Synthesis of compounds 7 and $\mathbf{8}$

Scheme 2: $\quad$ Synthesis of

A/ TOFP: meso (5,10,15,20-tetra(4-(4 methyloxyfluorenyl)phenyl)porphyrin 1

B/ OOFP: meso (5,10,15,20-tetra(4-(3,5 dimethyloxyfluorenyl)phenyl)porphyrin 2

Figure 1: $\quad$ Compounds 1, 2, 3, 4, 5 and 6

Figure 2: Hydrogen and carbon atom-labeling for the porphyrin ligands 1 and 2

Figure 3: $\quad$ a) Spartens plot of the molecular structure of $\mathbf{1}$ in comparison to compound 3

b) Spartens plot of the molecular structure of 2

Figure 4: $\mathrm{UV}$-visible absorption spectra for compounds 1, 2, 3 and 4, in $\mathrm{CH}_{2} \mathrm{Cl}_{2}$ at $25^{\circ} \mathrm{C}$

(2.6 $10^{-6} \mathrm{M}$ for TFP, 3 and normalized to the same absorbance for $\mathbf{1 , 2}$ and $\mathbf{4}$ ).

Figure 5: $\quad$ Photoluminescence spectra of free ligands 1, 2, 3 and $4\left(\sim 1.010^{-6} \mathrm{M}\right)$

in $\mathrm{CH}_{2} \mathrm{Cl}_{2}$ solution, at $25^{\circ} \mathrm{C}$, the emission spectra were cut above $800 \mathrm{~nm}$.

Excitation spectra of compounds $\mathbf{1}$ and $\mathbf{2}$

Table 1: Photophysical properties of the fluorenyl porphyrins 1, 2 and $\mathbf{3}$ in dilute $\mathrm{CH}_{2} \mathrm{Cl}_{2}$ solution at $298 \mathrm{~K}$, and of TPP, $\mathbf{4}$, under the same conditions for comparison 


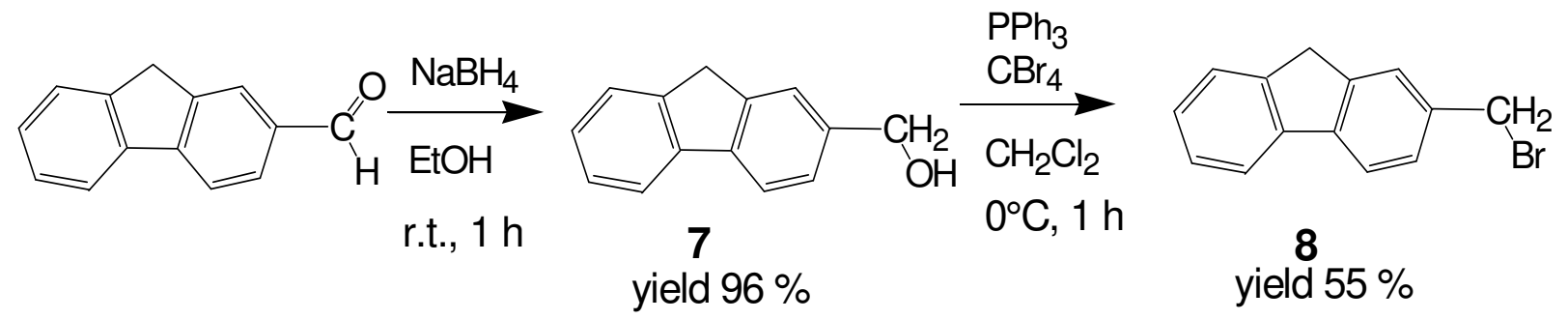

Scheme 1: Synthesis of compounds 7 and $\mathbf{8}$ 

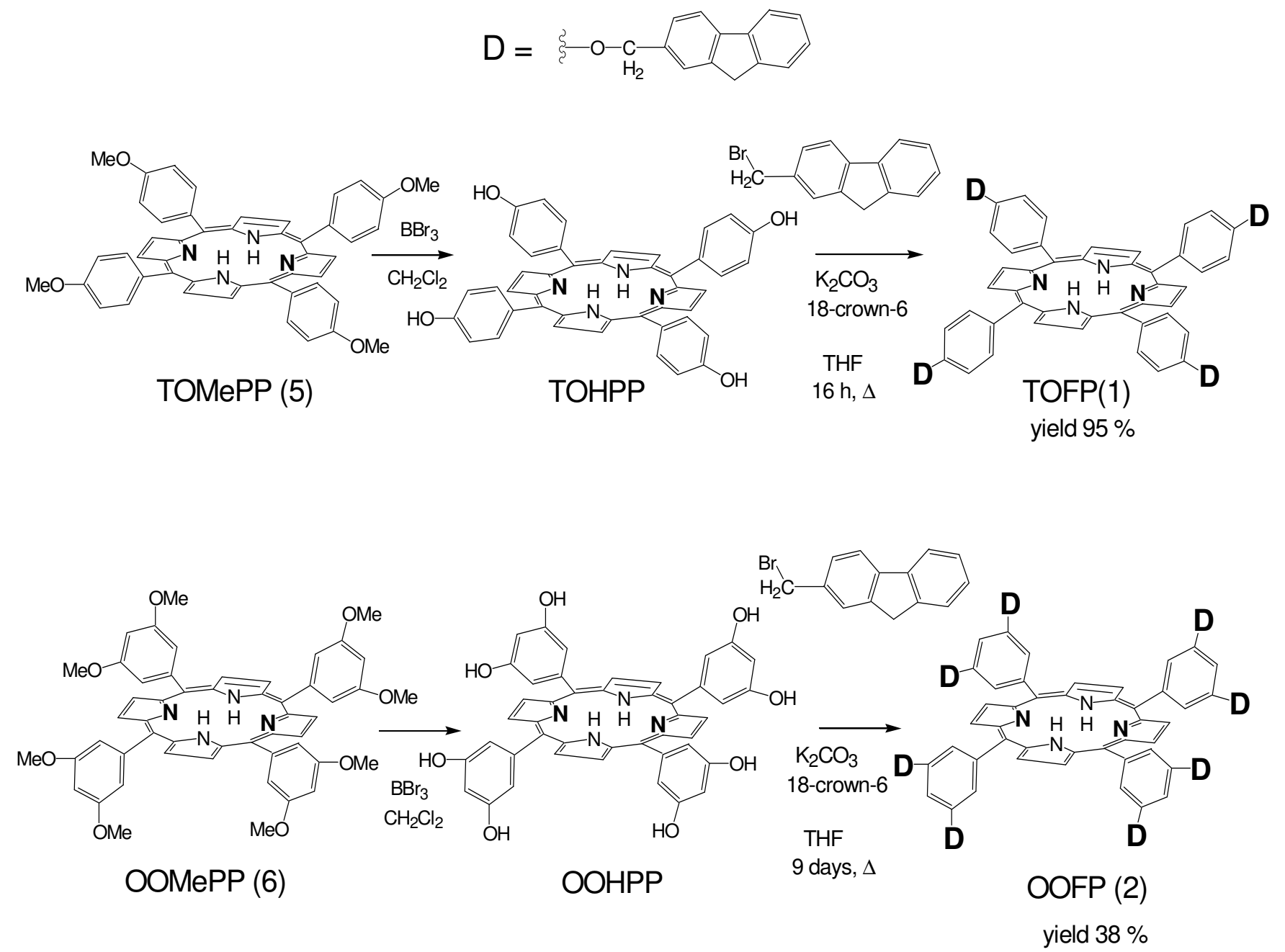

Scheme 2: Synthesis of porphyrins 1 and 2 


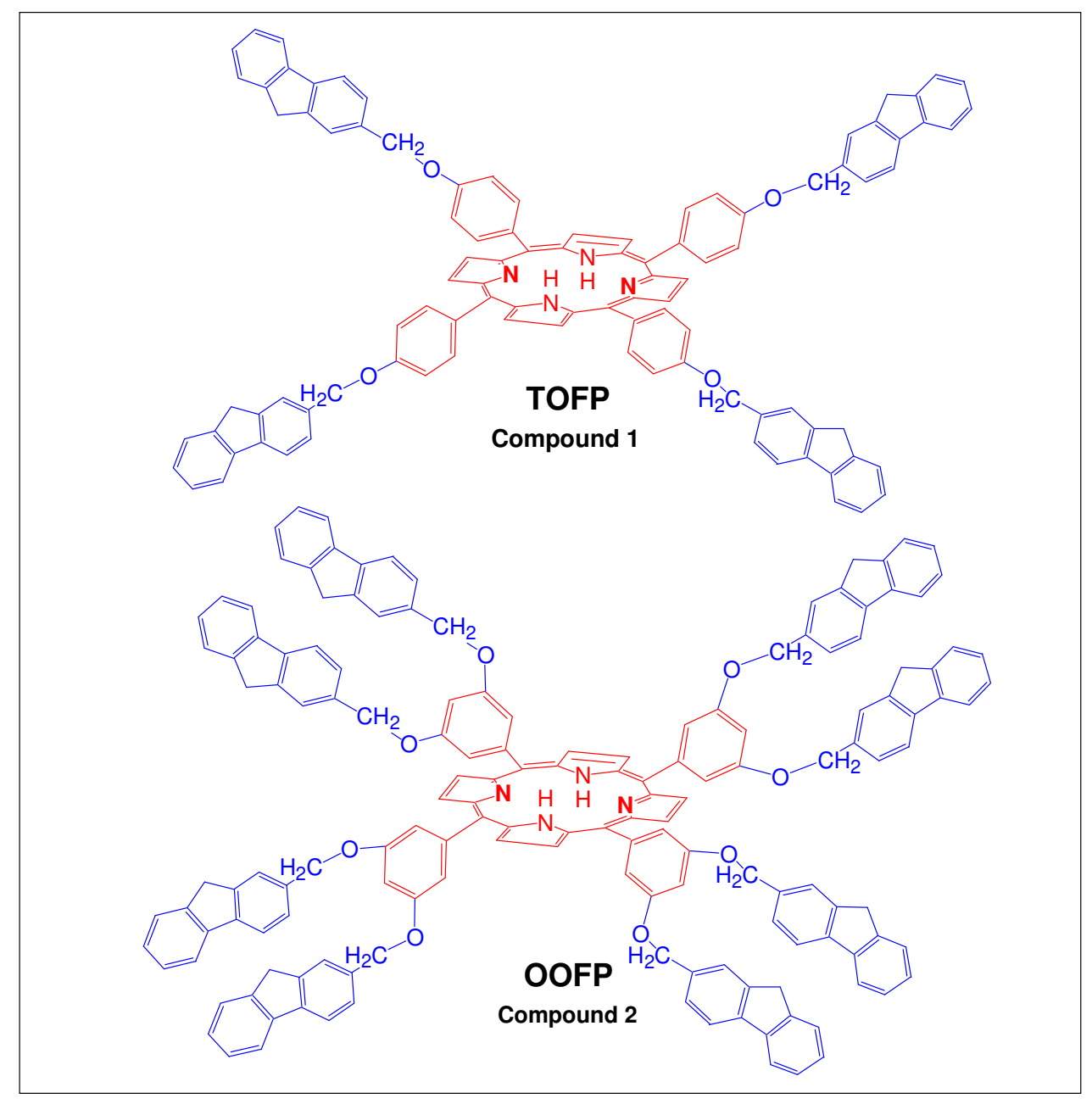

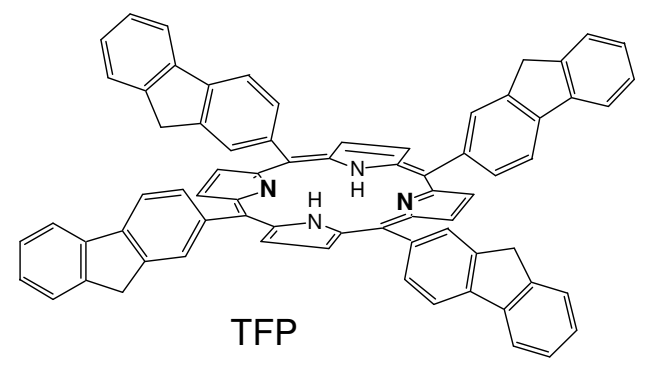

Compound 3

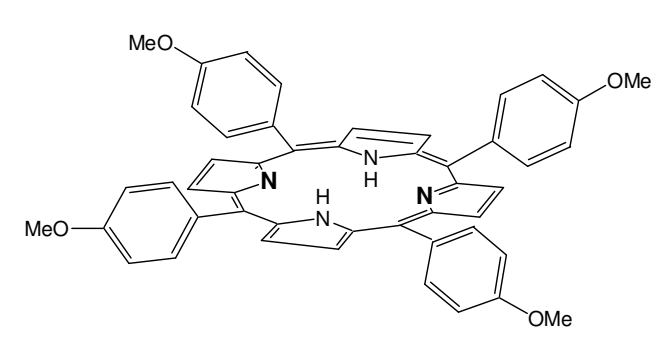

TOMePP

Compound 5

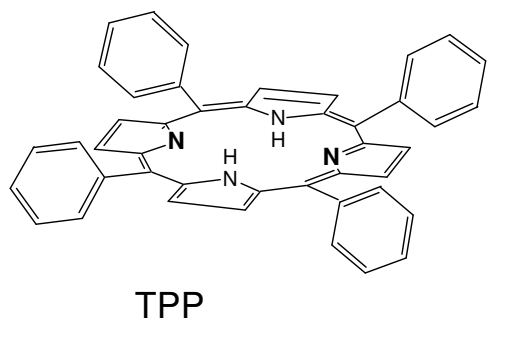

Compound 4

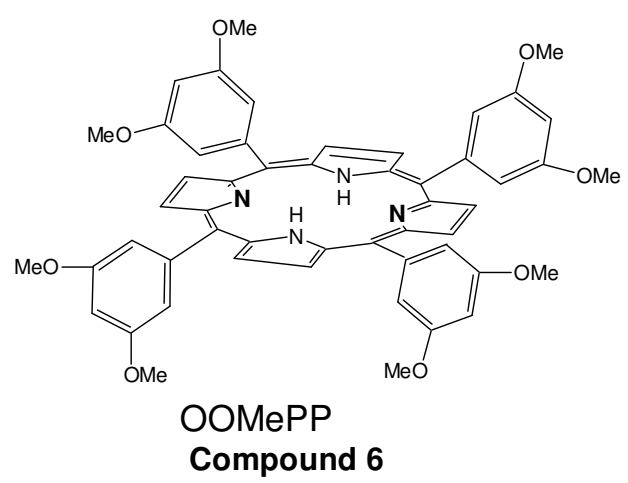

Figure 1 


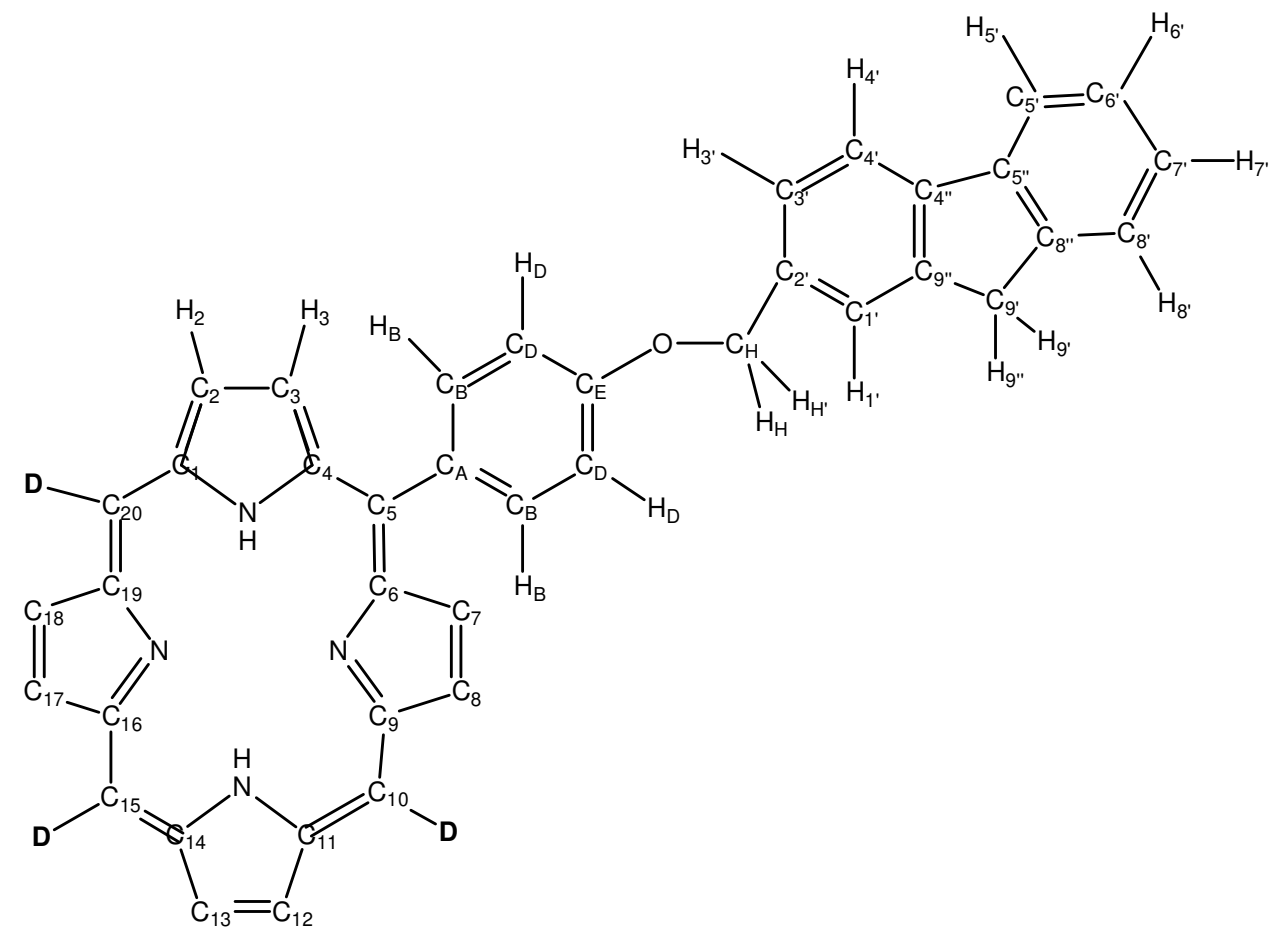

Compound 1

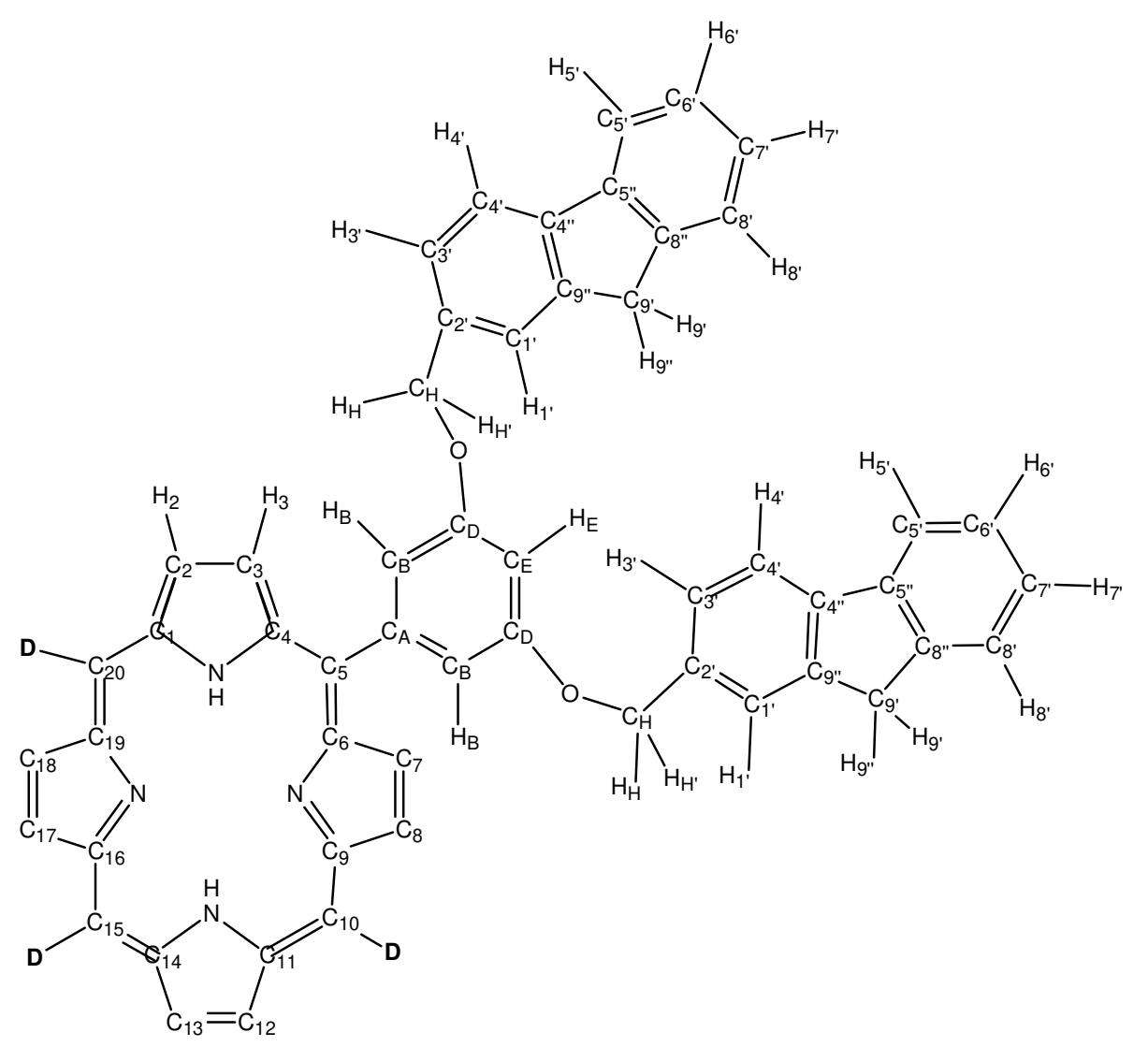

Compound 2

Figure 2 


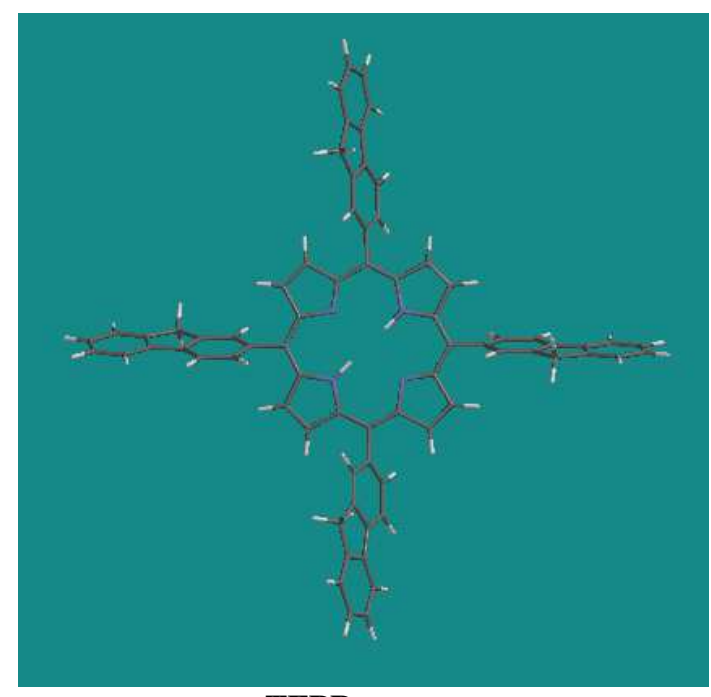

TFPP

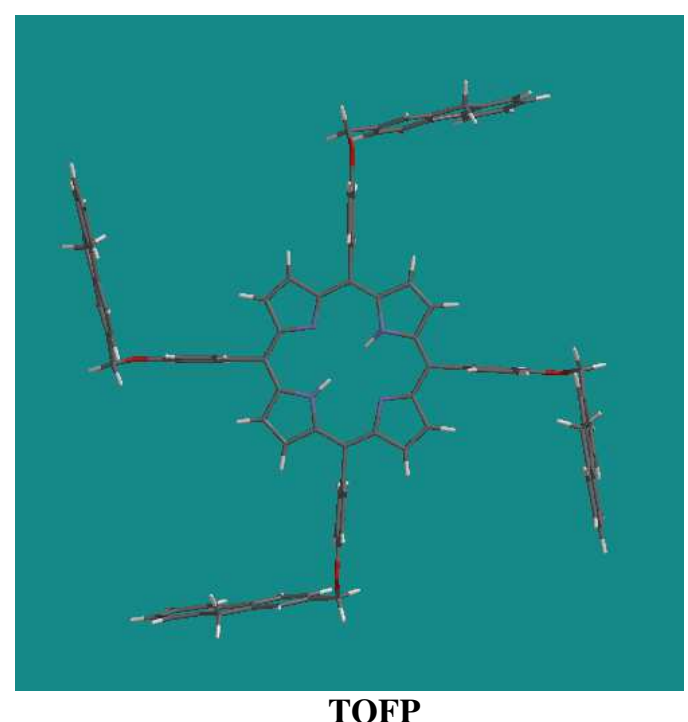

TOFP

Top view

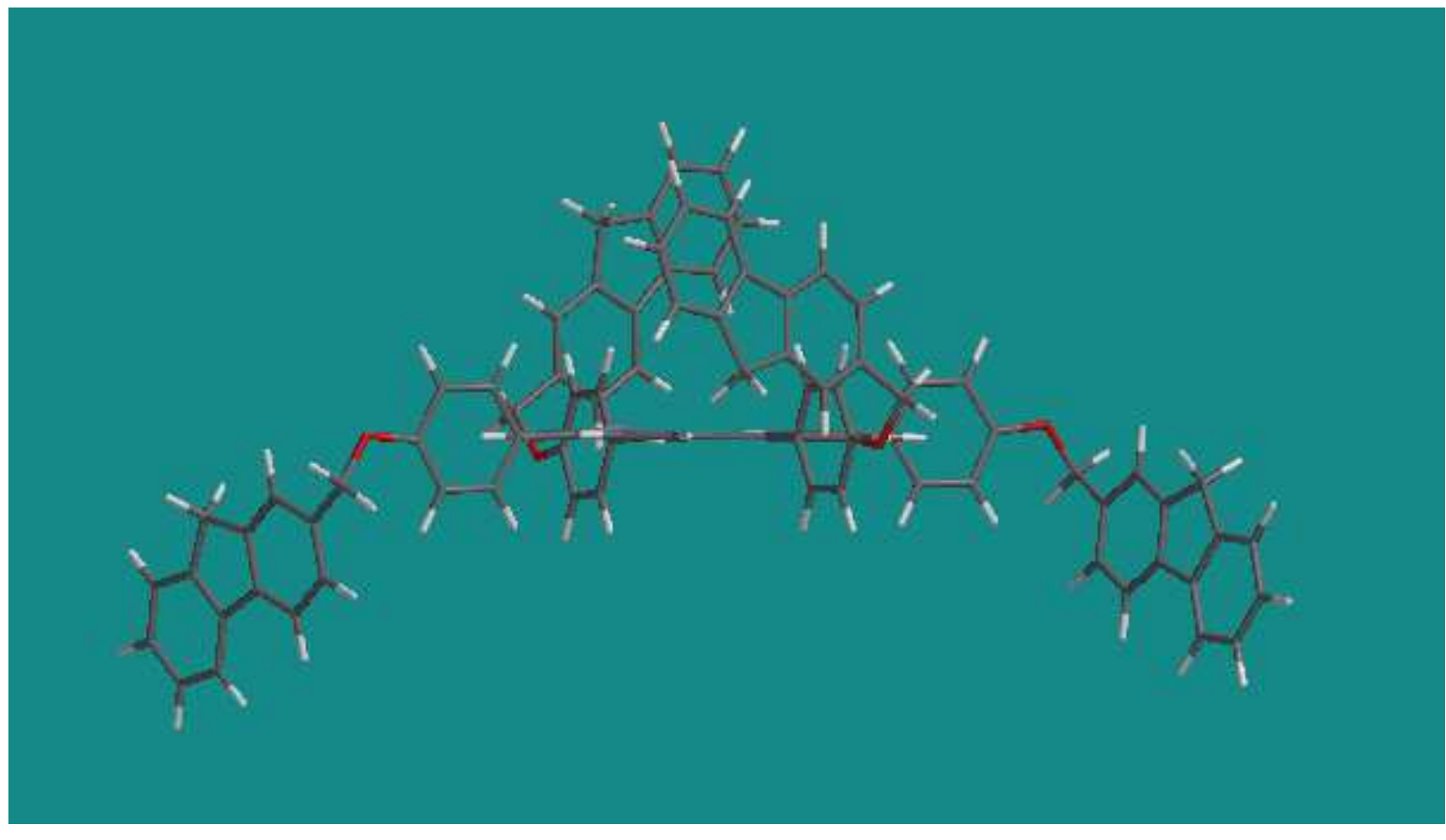

TOFP

Side view

Figure 3a 


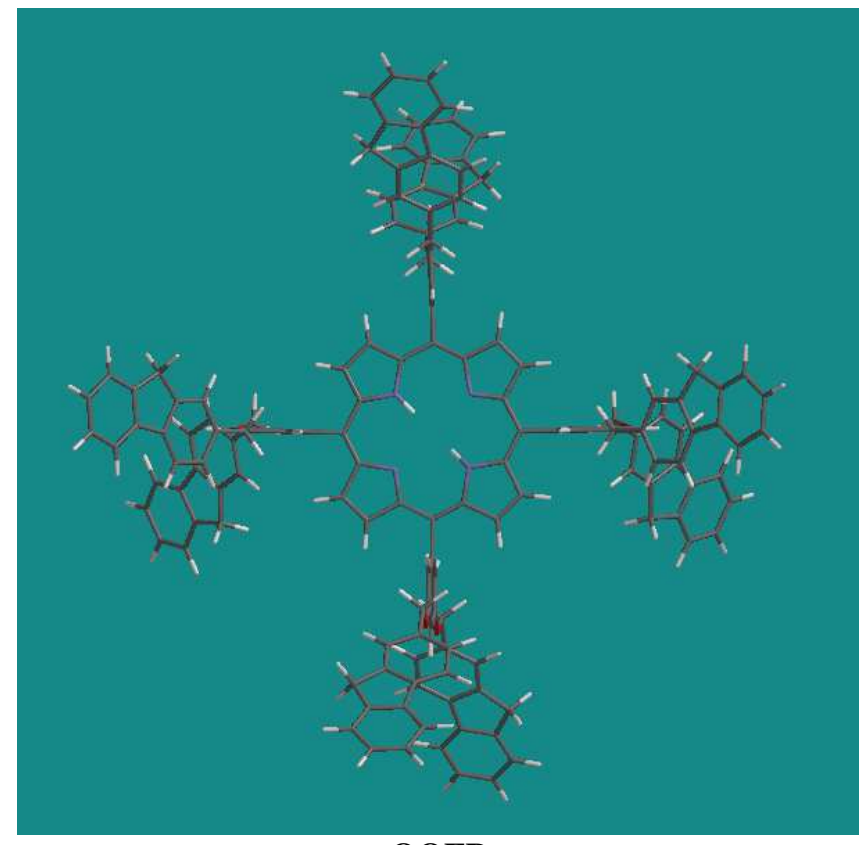

OOFP

Top view

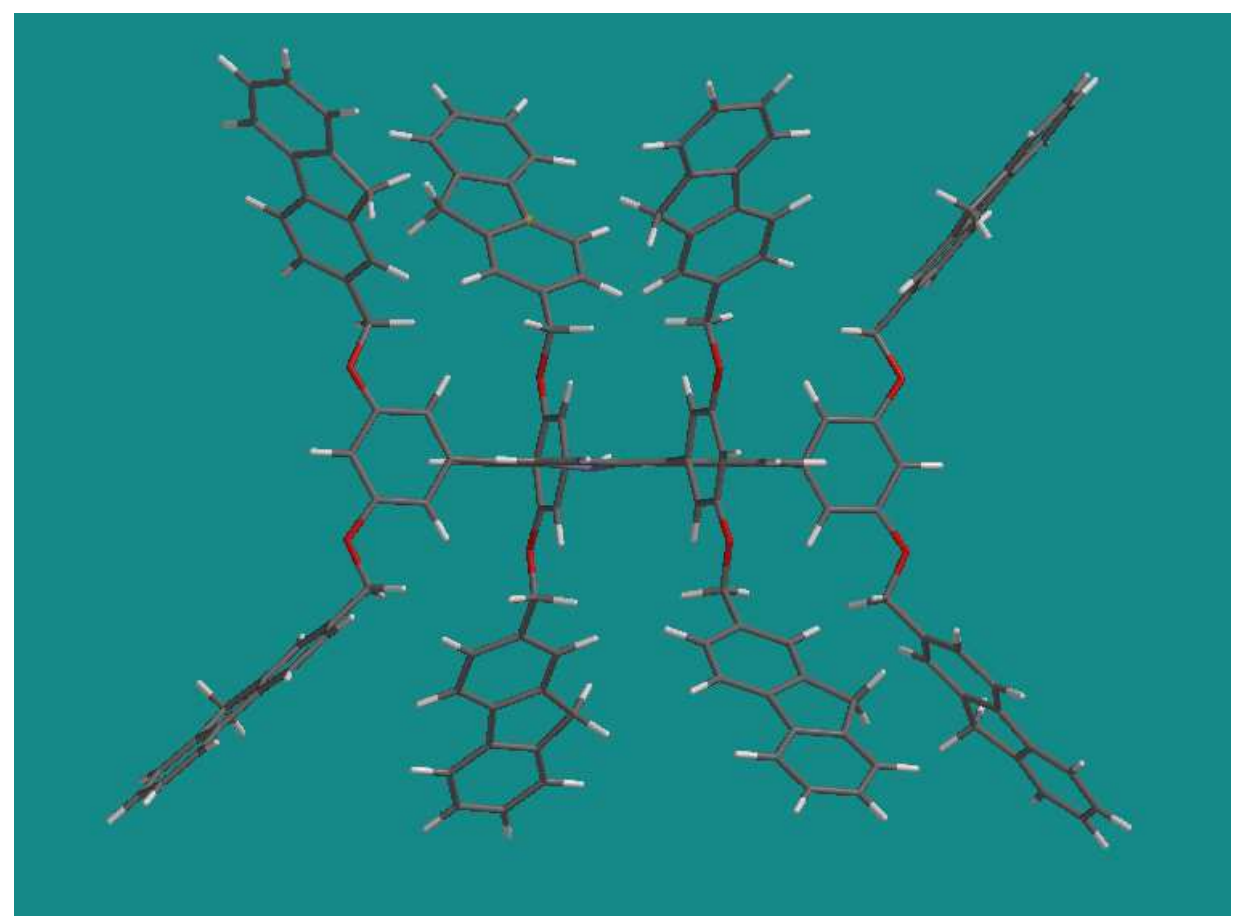

OOFP

Side view

Figure 3b 


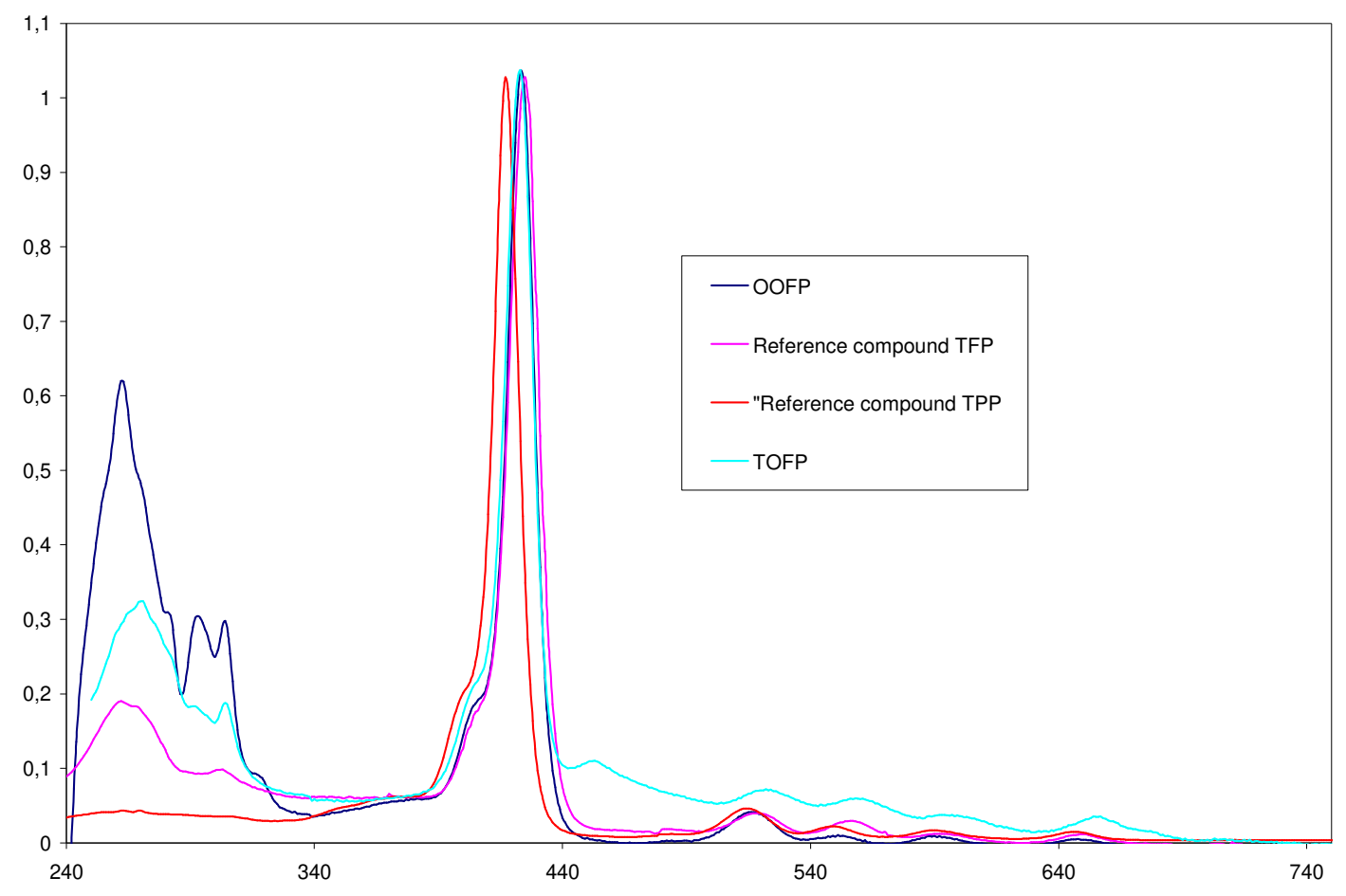

Figure 4 


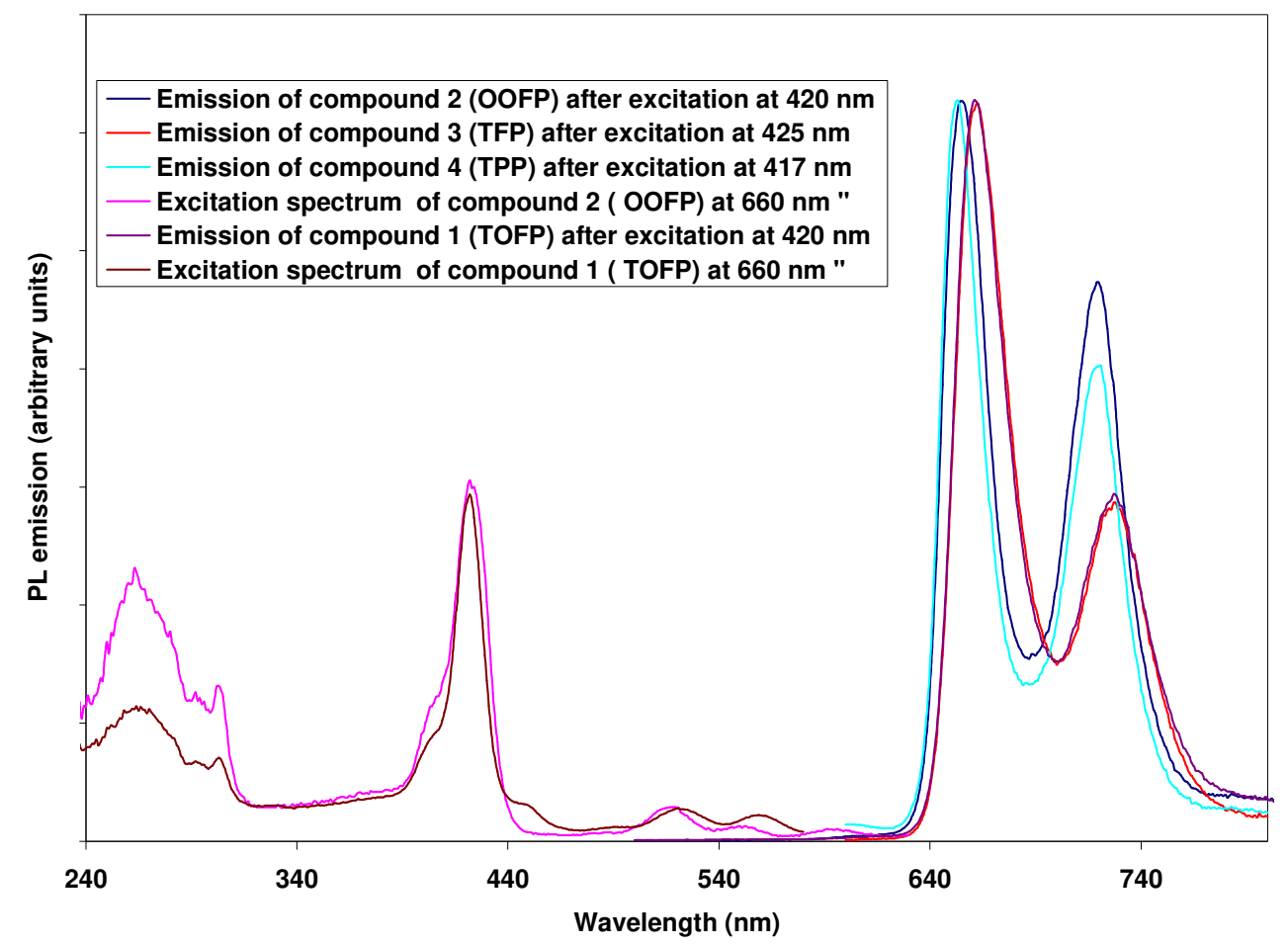

Figure 5 
Table 1: Photophysical properties of the fluorenyl porphyrins $\mathbf{1}, \mathbf{2}$ and $\mathbf{3}$ in dilute $\mathrm{CH}_{2} \mathrm{Cl}_{2}$ solution at $298 \mathrm{~K}$, and of TPP, 4, under the same conditions for comparison

\begin{tabular}{|l|c|c|c|c|}
\hline Porphyrin & TOFP (1) & OOFP (2) & TFP (3) & TPP (4) \\
\hline$\lambda_{\max } / \mathrm{nm}^{(a)}$ Soret band & 423 & 423 & 426 & 417 \\
\hline$\lambda_{\mathrm{em}} / \mathrm{nm}$ & 663,728 & 656,721 & 663,730 & 653,721 \\
\hline$\Phi_{\mathrm{f}}{ }^{(b)}$ & 0.10 & 0.13 & 0.22 & 0.12 \\
\hline
\end{tabular}

${ }^{a)}$ Wavelengths of the absorption maxima in the Soret or B band region (400-450 $\mathrm{nm}$ range)

${ }^{(b)}$ Fluorescence quantum yields in degassed solution, using TPP in toluene as standard, following excitation into the Soret bands 